\title{
Introduction to the Special Issue: Invited Papers from the 2015 APAHC Conference
}

\author{
Laura A. Shaffer ${ }^{1} \cdot$ Amit A. Shahane $^{2}$
}

Published online: 24 November 2015

(c) Springer Science+Business Media New York 2015

\begin{abstract}
The 7th biennial National Conference of APAHC, the Association of Psychologists in Academic Health Centers, was held in Atlanta, Georgia, February 5-7, 2015. Speakers were invited to contribute manuscripts based on their conference presentations, and many submitted manuscripts for this special edition of the Journal of Clinical Psychology in Medical Settings. Some papers will appear in the December 2015 issue of JCPMS; others will appear in the March 2016 issue. All papers have undergone a rigorous peer review process. The Conference Co-Chairs, Drs. Laura Shaffer and Amit Shahane, are Guest Editors for the special issue. In this article, they provide an overview of the conference's major themes, and also discuss some aspects of conference planning.
\end{abstract}

Keywords APAHC · Interprofessionalism · Academic health centers

This collection of papers is based on presentations at the seventh biennial National Conference of APAHC, the Association of Psychologists in Academic Health Centers, held in Atlanta, Georgia, February 5-7, 2015. Many of the invited speakers have contributed manuscripts based on their talks, which are being published in two successive issues of the Journal of Clinical Psychology in Medical Settings, in December 2015 and March 2016.

Laura A. Shaffer

laura.shaffer@virginia.edu

1 Department of Pediatrics, University of Virginia School of Medicine, P.O. Box 800828, Charlottesville, VA 22908, USA

2 Department of Psychiatry and Behavioral Sciences, Emory University School of Medicine, Atlanta, GA, USA
The Conference theme was interprofessionalism as a growing trend in academic health centers (AHCs) and psychology's role in that trend. We define interprofessionalism broadly as collaborative practice between healthcare professionals from diverse healthcare disciplines (D'Amour \& Oandasan, 2005). Central to the concept of interprofessionalism are the integration of otherwise disjointed health care practices to improve patient health outcomes, as well as inclusion of interprofessional components in training health professionals. This concept is not new to psychology, but the term "interprofessional" has become a unifying theme that serves to link multiple disciplines (e.g., psychology, medicine, nursing, and social work) with the aim of improving health care processes and outcomes. AHC psychologists fit well within the interprofessional paradigm given their diverse roles that include providing clinical service in multidisciplinary teams; teaching not only psychology trainees, but also trainees from other health professions; serving as members and leaders of multidisciplinary research teams; and filling administrative roles. Typically, psychologists perform these functions in concert with colleagues from other health professions and so position themselves in a complex network of interprofessional relationships in AHC settings.

The 2015 APAHC conference sought to highlight psychology's interprofessional contributions across multiple domains of academic health centers. The 2015 Conference also built upon past conferences' emphasis on health care reform and integrated care but went further in examining AHC psychologists' application of principles of interprofessionalism in their work. To this end, the conference Cochairs developed goals that guided planning for the 2015 conference. First, we invited speakers whose presentations covered a broad range of topics related to issues of training, administration, clinical service, and diversity that would 
interest psychologists at all stages of their careers. Second, in keeping with the theme of interprofessionalism, we invited non-psychologists to give presentations as well as psychologists. Third, we increased the representation of child clinical and pediatric psychology among conference speakers and topics so as to attract more pediatric psychologists to the conference. Thus, nearly half the speakers at the 2015 conference identified as child or pediatric psychologists, as compared to one-fourth of the speakers at the previous 2013 APAHC conference. Last, we aimed to keep the collegial and lively atmosphere of past conferences by holding the conference at a small venue and ensuring plentiful opportunities for interaction between attendees and speakers following talks, during meals, breaks between sessions, and in breakout groups.

The conference opened with keynote addresses by two national leaders who have been strong proponents of interprofessionalism and integrated health care. David Satcher, former Surgeon General of the United States, discussed progress and challenges relating to reducing stigma surrounding mental health issues and improving quality and access to care through integrated care models. Nadine Kaslow, Past President of the American Psychological Association (APA), then spoke more specifically about the role of psychology in patient centered medical homes and the optimal integration of psychologists into this interprofessional team model.

The first full day of the conference began with an examination of ways that psychologists can expand the reach of their work. Carol Webb and Janet Orwig presented on telehealth and its implications for professional licensure for psychologists. They provided an overview of recently developed guidelines and standards for the practice of telepsychology, and they proposed strategies for practicing telepsychology across jurisdictional lines. Next, Jim DiazGranados, Executive Director of APA's Education Directorate, discussed the need for education and training that will prepare psychologists for working in an increasingly integrated healthcare system.

One of the growing challenges for psychologists in academic health centers is the demand to quantify our work, be that in terms of clinical productivity, clinical outcomes, or teaching time. Presentations by Gene D'Angelo and Lisa Kearney proposed strategies for measuring the quantity and value of psychologists' work in academic health centers. Dr. D'Angelo reviewed models for incorporating Educational Value Units (EVUs) into psychology positions as a method for capturing the education, training, and scholarship facets of psychologists' work in ways that parallel the use of Relative Value Units (RVUs) to capture their delivery of clinical services. Lisa Kearney discussed measuring clinical outcomes with screening and brief assessment tools in integrated care settings. She also described methods for measuring administrative and managerial outcomes such as productivity, resource utilization, efficiency, and health care cost reduction. Psychologists in academic health centers are increasingly being called upon to develop and implement methods for program evaluation in these areas.

The central clinical topic for the 2015 conference was depression. In keeping with the interprofessional theme, talks in this conference segment covered topics such as biological underpinnings of depression, depression subtypes and their differential implications for assessment and treatment, interprofessional program development, and treatment applications for depression. Psychiatrist Andrew Miller provided an overview of research on immune activation and cytokine effects on brain function and behavior that may contribute to high rates of depression, anxiety, and other behavior changes in medically ill and chronically stressed individuals. Dr. Miller and his colleagues suggest the possibility that pathologies related to these conditions might be treatable by interventions that target the immune system and inflammation rather than by more conventional medical treatments for depression. Next, Edward Craighead presented his work on neural subtypes of depression in adolescence and their links to mechanisms of change. Dr. Craighead underscored the importance of interprofessional collaboration, integration of science and practice, and working in concert with the community. His colleague, Cynthia Ramirez, extended these themes with an applied example through her description of a dialectical behavior therapy (DBT) outpatient program for adolescents who struggle with emotion dysregulation or engage in nonsuicidal self-injury.

The Conference also featured an in-depth presentation on ethics by Don Brunnquell, Director of the Office of Ethics at the Children's Hospitals and Clinics of Minnesota. Dr. Brunnquell highlighted psychologists' unique position in academic health centers and their potential to play a role in identifying areas of moral distress and assisting interprofessional colleagues in dealing with such concerns. He encouraged psychologists in academic health centers to serve on ethics committees and participate in ethics discussions and consultations.

The first full day of the conference concluded with updates on APAHC activities and a session for mid-career psychologists on ways to enhance prospects for promotion. First, Ron Brown, 2014-2015 President of APAHC, and other Board members gave an overview of recent activities in the organization including revision of the bylaws and research efforts and presentations linked to the Association of American Medical Colleges (AAMC) and the American Psychological Association's Center for Workforce Studies. Then, in keeping with APAHC's strong tradition of mentoring, four of our more experienced members partnered 
with mid-career attendees to provide feedback regarding ways to improve their $\mathrm{CVs}$ and further their career development.

The next morning, the conference focused on integrated primary care, a topic that has been a mainstay on the program of the two preceding APAHC conferences as well as a focus of the work of many APAHC members (e.g, Kessler \& Cubic, 2009; McDaniel et al., 2014). The 2015 conference focused on challenges faced when implementing various models of integrated care and when building on foundational work on integrated primary care in family medicine. Issues of funding were addressed by Benjamin Miller. He presented promising payment models that support the value of integration and ways for psychologists to make a business case for integrating their services in medical settings. In recent years, there has been increased attention to integrated primary care in pediatrics. Lynne Sturm, Co-Chair of the APA Division 54 Task Force on Pediatric Integrated Primary Care, provided a summary of developments in this area. She described the task force's efforts to develop psychological competencies specific to pediatric integrated primary care based on foundational documents that outline more broadly competencies in integrated primary care (McDaniel et al., 2014) and pediatric psychology (Palermo et al., 2014).

The diversity focus for the 2015 conference involved an exploration of ways that psychologists in academic health centers can help interprofessional teams better meet the healthcare needs of the lesbian, gay, bisexual, and transgender (LGBT) community. There has been increased attention to health disparities among LGBT individuals as a result of the Institute of Medicine's 2011 report, goals set by the national Healthy People 2020 report (U.S. Department of Health and Human Services, 2012), and a 2013 brief from the American Psychological Association recommending training for psychologists to better address LGBT health disparities (APA Public Interest Government Relations Office, 2013). Arlene Noriega, Past President of APA Division 44, provided an overview of strategies for reducing such disparities, and Terry Stancin then gave a presentation on psychologists' roles in the treatment of transgender youth with a focus on her team's work in a hospital-based interprofessional clinic for gender variant children and adolescents (Cousino et al., 2014).

The final addresses of the conference targeted issues of psychologists' contributions to leadership and career development in academic health centers. Patrick Smith reviewed the underpinnings of the transformational-transactional continuum of leadership and encouraged participants to adopt more of a transformational leadership model (Souba, 2011). Then, in homage to David Letterman's retirement, Barry Hong presented his top ten tips for psychologists to live a long, happy life at an academic health center, and to help keep psychology visible, relevant, and integrated throughout academic health centers.

The final event of the seventh national APAHC conference consisted of three breakout discussions conducted in parallel and organized around separate themes: the Business of Practice, Leadership and Administration, and Training and Mentoring. Each breakout group was composed of a mix of early, mid, and later career attendees and provided participants the opportunity to share experiences and reflect on ideas generated over the course of the conference.

Having provided an overview of the 2015 APAHC Conference, we turn again to this special issue of papers based on Conference presentations. Each of the five Conference-based papers in this issue of JCPMS provides a comprehensive, in depth view of topics presented by invited speakers. An additional set of Conference-based papers will be published in the Journal's next issue, in March 2016. Those papers will cover presentations by other speakers at the 2015 Conference. All of the papers present useful information for JCPMS readers, but they are intended to do more than that. They also capture the essence of the Conference, not only in content, but also with respect to the collaborative and collegial spirit of APAHC as a professional association. APAHC has served as a home base for psychologists working in academic health settings that range from teaching hospitals and medical schools to Veterans Health Administration facilities (Silver et al., 2005). With an emphasis on interprofessional healthcare, APAHC has advocated for psychology's value and presence in academic health centers. The 2015 APAHC Conference reflected this advocacy by highlighting psychologists' work and contributions in these centers.

Acknowledgments The authors are pleased to acknowledge sponsors of the 2015 National APAHC Conference: the National Register, the American Board of Professional Psychology, the Health Psychology Division 38 of APA, the Society for Clinical Neuropsychology (Division 40), and Taylor Study Method. We also thank other members of the APAHC Board of Directors for their support: Ron Brown, Ph.D., ABPP; Catherine Schuman, Ph.D.; Barbara Cubic, Ph.D.; Donna Lapaglia, Psy.D.; Alfiee Breland-Noble, Ph.D.; Cheryl Brosig, Ph.D.; Zeeshan Butt, Ph.D.; Kelly Foran-Tuller, Psy.D.; Laura Daniels, M.A.; Sharon Berry, Ph.D.; and Gerald Leventhal, Ph.D. Last, we express special appreciation to our fellow Conference Committee members for their hard work and good humor over the two-years of planning for the seventh National APAHC Conference: Stephanie Power, Ph.D.; Lauren Penwell-Waines, Ph.D.; Kristine Diaz, Ph.D.; Teresa Fecteau, Ph.D.; and Liz Cash, Ph.D.

\section{Compliance with Ethical Standards}

Conflict of Interest Laura A. Shaffer and Amit A. Shahane declare that they have no conflict of interest. 
Human and Animal Rights and Informed Consent No animal or human studies were carried out by the authors for this article.

\section{References}

APA Public Interest Government Relations Office. (2013). LGBT health disparities. Washington DC: The American Psychological Association.

Cousino, M. K., Davis, A., Ng, H., \& Stancin, T. (2014). An emerging opportunity for pediatric psychologists: Our role in a multidisciplinary clinic for youth with gender dysphoria. Clinical Practice in Pediatric Psychology, 2, 400-411. doi:10.1037/ cpp0000077.

D'Amour, D., \& Oandasan, I. (2005). Interprofessionality as the field of interprofessional practice and interprofessional education: An emerging concept. Journal of Interprofessional Care, Supplement, 1, 8-20.

Kessler, R., \& Cubic, B. (2009). The train is leaving the station: is psychology aboard? Journal of Clinical Psychology in Medical Settings, 16, 1-3. doi:10.1007/s10880-009-9157-8.
McDaniel, S. H., Grus, C. L., Cubic, B. A., Hunter, C. L., Kearney, L. K., Schuman, C. C., et al. (2014). Competencies for psychology practice in primary care. The American Psychologist, 69, 409-429. doi:10.1037/a0036072.

Palermo, T. M., Janicke, D. M., McQuaid, E. L., Mullins, L. L., Robins, P. M., \& Wu, Y. P. (2014). Recommendations for training in pediatric psychology: Defining core competencies across training levels. Journal of Pediatric Psychology, 39, 965-984. doi:10.1093/jpepsy/jsu015.

Silver, R. J., Carr, J. E., \& Leventhal, G. (2005). History of the Association of Medical School Psychologists (ASMP), 1982-2005. Journal of Clinical Psychology in Medical Settings, 12, 235-245.

Souba, W. (2011). Perspective: a new model of leadership performance in health care. Academic Medicine: Journal of the Association of American Medical Colleges, 86, 1241-1252. doi:10.1097/ACM.0b013e31822c0385.

U.S. Department of Health and Human Services (2012). Lesbian, gay, bisexual, and transgender health. Retrieved from http://www. healthypeople.gov/2020/topicsobjectives2020/overview.aspx?to picid $=25$. 